\title{
Roundabout Homolog 3
}

National Cancer Institute

\section{Source}

National Cancer Institute. Roundabout Homolog 3. NCI Thesaurus. Code C126779.

Roundabout homolog 3 (1386 aa, $148 \mathrm{kDa}$ ) is encoded by the human ROBO3 gene. This protein is involved in the modulation of neurite outgrowth and axon guidance. 